\title{
3 Literature Survey
}

Architecture is a wonderful means of representing, imposing or arousing states of human nature. (Eurozine, 2011)

\subsection{Overview}

My work establishes how the innate potency of the material world may be applied to architectural design practice. I aim to identify experimental models to test this hypothesis and set out the principles that underpin the proposed modes of action that may be practically applied in an architectural design context, through the production of collaborative drawings, models and prototypes. My literature search, therefore, explores the overlapping fields of chemistry, which may be regarded as the 'language' of matter, and architecture, which is concerned with the tactics for developing spatial programs. In juxtaposing these disciplines to find synergies between them, my research aims to identify gaps in the knowledge canons and therefore establish the research opportunities. Omar Khan observes the many historic technological and cultural instances where chemistry is entangled with architecture to create something new in the production of new materials, such as concrete, steel, plastics, rubber, crystals and fluids with mutable structures (Khan, 2011). Architect William McDonough and chemist Michael Braungart combine architecture and chemistry in their 'Cradle to Cradle' manifesto, which proposes that more efficient management and better design of the production process may achieve ecologically intelligent design (McDonough and Braungart, 2002). While I share the material concerns of McDonough and Braungart, my research is not focused on the transformation of industrial processes or 'upcycling' through the cultural (re)usage of waste materials, but in the direct empowerment of matter. Rather, I use an alternative framework to the industrial worldview by applying design principles that are expressed through process philosophy and whose operations are embodied in complexity science.

My literature survey therefore establishes a roadmap of connections between the disciplines of architectural design and chemistry, with the purpose of understanding what kinds of matter may be sufficiently lively to produce effects that can be designed and measured at the human scale. Material systems are identified that embody the principles of vibrant matter and applied in an architectural setting. My reading also draws from a wide range of disciplines such as philosophy, ecology, complexity, origins of life sciences, sociology and physics, to more fully characterize any apparent knowledge 'gaps'. Taking a processes-oriented rather than object-centred perspective, also allows experiments to be described without invoking machine metaphors. A rich range of terms and ideas are invoked that embody the term 'vibrant matter' and collectively shape my approach to developing a unique portfolio of design operations (see Fig. 3.1).

\section{(cc) BY-NC-ND (C) 2015 Rachel Armstrong}

This work is licensed under the Creative Commons Attribution-NonCommercial-NoDerivs 3.0 License. 


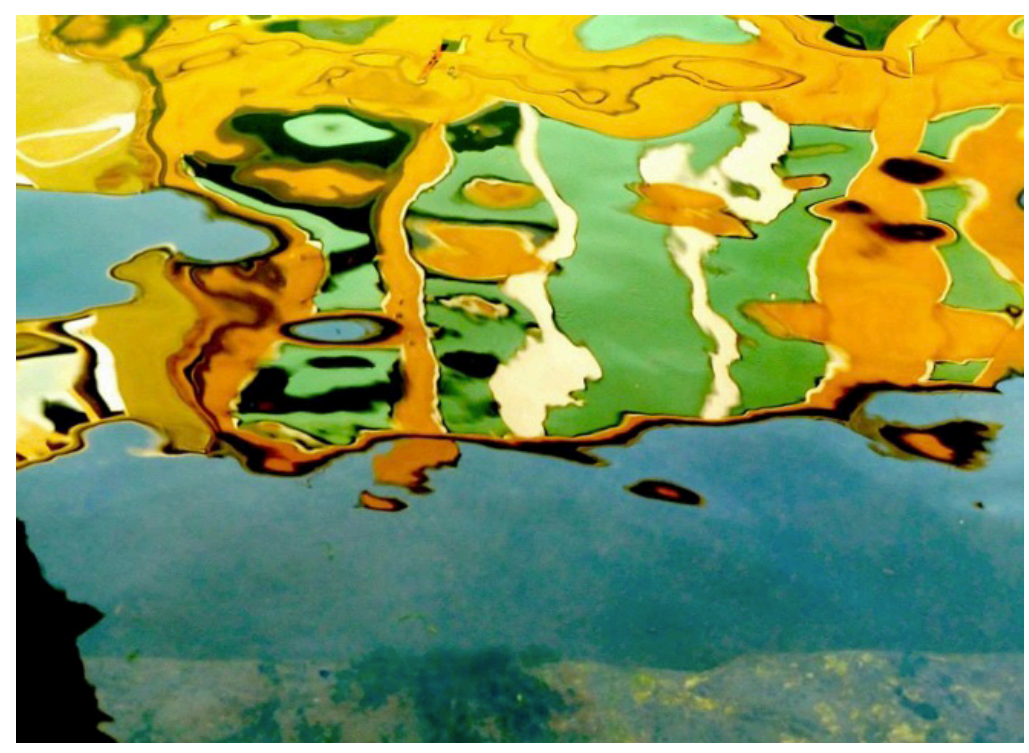

Figure 3.1: This Venice canal reflection captures aspects of the complex interplay between environment and architecture that is continually orchestrated by the physical and chemical forces of the natural world. Photograph, Rachel Armstrong, August 2012.

\subsection{Information Sources}

A wide variety of information sources are used, ranging from academic journals, reference books, news websites to special interest blogspots. They identify knowledge canons, as well as keeping up to date with the latest cultural and scientific developments. My reading is concerned both with new findings in the literature and the curating and re-positioning of existing ideas with different disciplines, such as the relationship between quantum physics and vitalism in reference to the dynamic nature of materials (Armstrong, 2012c). To quickly get a feel for a subject area I attended international conferences that drew together expert views on the latest research. For example, 'Artificial Life XI' inspired the model system for my studies of vibrant matter following Takashi Ikegami's keynote address on dynamic droplets (Ikegami, 2008), and 'Prototyping Architecture' by Bob Sheil at the Building Centre, London (Murphy, 2013) discussed the relevance of emerging technologies to architectural design practice. I participated in laboratory discussions, attended academic presentations and panel discussions that engaged with overlapping fields of interest, such as Liam Young and Geoff Manaugh's ‘Thrilling Wonder Stories’ series at the Architectural Association (Thrilling Wonder Stories, not dated). This established the broadest possible context for my evolving architectural design and chemistry research questions, which, in turn, directed my further reading and research. 


\subsection{Critical Context}

\subsubsection{Overview}

My literature survey draws from four broad fields of study:

- Organicism: establishing the historical context for vibrant matter in the field of architectural design practice.

- Bio Design: identifying how dynamic materials are incorporated into buildings, projects and products.

- Vibrant materials: characterizing the kinds of substrates that embody the principles of vibrant matter.

- Morphological computing: developing a portfolio of manipulation techniques so that vibrant matter can be practically applied and tested in scientific experiments and architectural prototypes.

\subsubsection{Organicism}

Organicism refers to the design practice that seeks more Nature-like approaches (Capra, 1996) to the production of spatial programs and proposes an alternative paradigm to the machine-based construction that underpins modern architecture. Throughout the ages, architectural design has looked to Nature as an ideal through typological forms such as Marc-Antoine Laugier's sublimated references to essences of the natural world, which were driven by aesthetic values like archetypes (primitive hut), idealized proportioning systems (Golden Section), anthropomorphic imitation (Vitruvian Man) and literal forms of ornamentation, geological stratification (base, middle, top), and materials (undressed stone). Yet morphological abstractions and discrete typologies are mired in cultural aspirations (Morton, 2007) and do not directly embody the dynamic material properties of the living world, such as growth, movement or evolution.

I therefore surveyed 20th and 21st century design movements to establish how lifelike qualities may have been directly incorporated into architectural design practice. The anthologies of architectural theory written by Kate Nesbitt (Nesbitt, 1996) and K. Michael Hays (Hays, 2000) offered accessible surveys of western architectural debates during the late 20th century. George Baird outlines the different concerns within the modern tradition of organicism, such as how natural systems build across scales and different material regimes (Baird, 2003). Sarah Bonnemaison and Philip Beesley further critiqued organicism's main interests, proposing that the work of Richard Buckminster Fuller, Pierre Teilhard de Chardin and Frei Otto best characterized key perspectives within this movement (Beesley and Bonnemaison, 2008). Beesley and Bonnemaison suggest that Buckminster Fuller champions a mathematically inspired vision of Nature (Fuller, 1969), while de Chardin embodies 
the environmental concerns of New Age philosophy (De Chardin and Huxley, 2008) and Frei Otto represents the process-led, environmentally-sensitive maker movement (Otto, 1996). I was also interested in morphogenetic debates that examined how the relationship between architectural program and structure were being imagined in the production of generative architectures (Frazer, 1995). These discussions embodied contemporary scientific ideas about living systems between neo-Darwinists such as Richard Dawkins who viewed genes as being the primary organizing force of matter (Dawkins, 1976), and biological structuralists such as Brian Goodwin and Conrad Waddington (Waddington,1957). These key architectural debates also reflect important and parallel scientific discussions regarding the paradox of biology, which appears to contravene the second law of thermodynamics ${ }^{16}$ (Schrödinger, 1944) in ways that were not observed in the physical and chemical sciences ${ }^{17}$ and even locally resists the decay towards equilibrium. My reading, therefore, investigated how architectural design practices have captured the paradoxical qualities of biological systems, which are lively because they are not at equilibrium states. Indeed, traditional building practices incorporate biology directly into architectural solutions, such as the living bridges of Cherrapunji, where powerful ropey root tendrils of the Ficus elastica tree are entwined to span rocky gullies. ${ }^{18}$ However, native biological systems pose significant design challenges in urban environments. For example, organisms require a constant flow of nutrients and removal of waste products and - compared with mechanical construction methods - grow slowly, thereby exhibiting 'slowness', one of Bennett's qualities of vibrant matter (Bennett, 2011). Architects have therefore tried to capture the unique essence of living systems through many different approaches to expressions of form, such as Art Nouveau's stylization with its biological motifs carved into traditional materials. Notably, Antonio Gaudí developed a dynamic set of material processes that could capture natural qualities by suspending clay in hanging baskets and letting physics and chemistry, the drivers of biology, work on the setting material. This approach produced primordial organic forms, which he then

16 The second law of thermodynamics assumes a closed system, which organisms are definitely not: consider the need for sustenance and how living things respond to changes in their environment.

17 Several authors observed the paradox of the poetry of biology and the mathematics underpinning physical and chemical systems, notably the French philosopher Henri Bergson in L'Evolution Créatrice (1922). Bergson proposed an anti-mechanistic worldview that celebrated Life as an improbably diversity-creating whole, animated by a powerful élan vitale. He also suggested that these forces were responsible for accelerating biological coevolution, which transformed the inert matter of the Earth's surface into living systems in a way that appeared to violate the second law of thermodynamics, which speaks about the conservation of energy in a system (Bergson, 1922, p.44).

18 Like many others in the banyan family, F. elastica (often called the rubber fig) has secondary roots that grow above the soil surface. By guiding these roots across chasms, villagers can slowly grow a strong, permanent bridge that can support 50 people and reach 30 metres in length. Such a bridge may take 15 years to grow and is fine-tuned to its niche environments. 
incorporated into the façade of the Sagrada Família cathedral in Barcelona, which is still under construction (see Fig. 3.2).

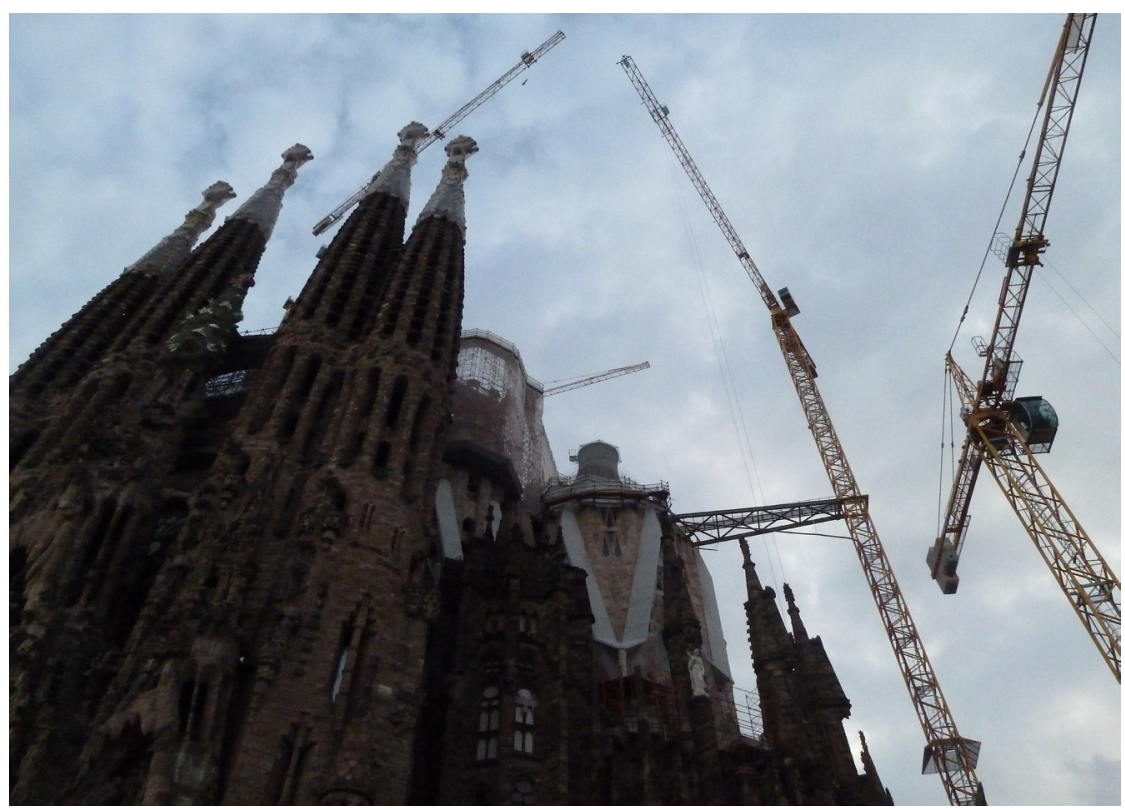

Figure 3.2: Gaudî’s La Sagrada Familia cathedral, which is growing ‘organically' and still under construction, incorporates organic motifs. Photograph, Rachel Armstrong, November 2011.

By applying this approach Gaudí reversed conventions of order in the process of building an architecture, which usually follows a top-down approach where form is imposed upon matter. Instead, Gaudí let the individual shapes of the set clay inform the final appearance of the building, which was Gaudî's hallmark organic style, which, for example, incorporated the use of mosaics (Burry, 1993) (see Fig. 3.3).

The rise of modern computing and the discovery of the genetic code over the second half of the 20th century enabled architects to experiment with mathematical principles used to describe natural forms (Thompson, 1917), which became an increasingly testable proposition with the advent of graphical user interfaces. Increasingly, biological systems could be considered as soft, wet, efficient, purposeful machines (Nicholson, 2009), which could therefore be assimilated within industrial frameworks. Indeed, the current sustainable architecture movement, which may be thought of as a 'better' kind of industrialization originating in the work of Frank Lloyd Wright (Weintraub and Hess, 2012), Alvar Aalto (Ray, 2005), Ludwig Mies van der Rohe (Zimmerman and Gossel, 2007) and R. Buckminster Fuller (Fuller, 1969), who believed architectural design could increase the material efficiency of the 

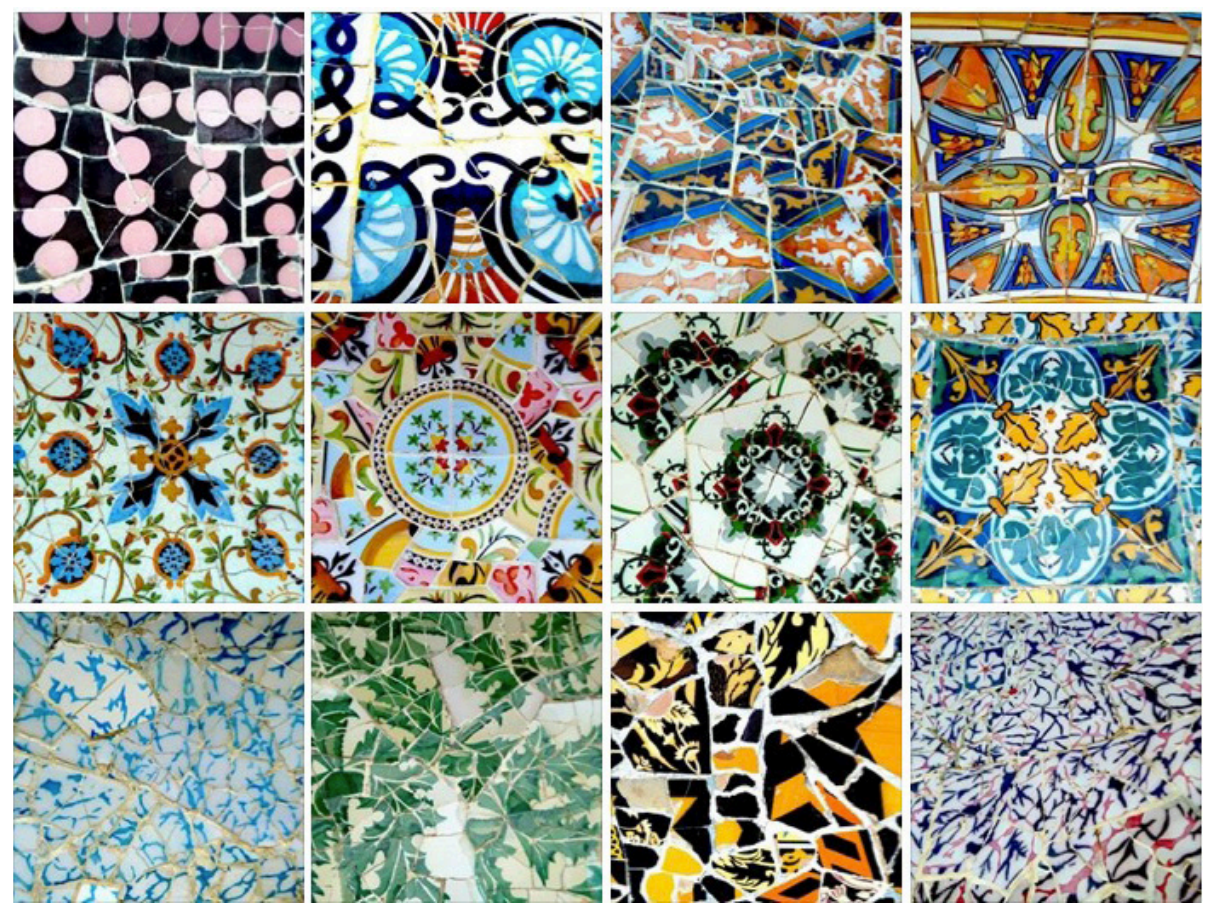

Figure 3.3: Gaudí’s mosaics in Park Guell adopt a 'cellular' approach in their designs. Photograph, Rachel Armstrong. November 2011.

natural world while emulating its forms 'as if' (Vaihinger, 1968) the buildings were organisms. Indeed, Emilio Ambasz proposed that 'green over grey' architectures not only subsumed the artificiality of architecture but also constituted 'artificial natures' (Dean, 2011, p.230). Yet this synthetic Nature is one of form rather than process, being obedient to abstracting geometrical principles from single moments in time that are (re)presented in architectural contexts and guided by Enlightenment ideals. For example, Casa de Retiro Espiritual, Seville (1978), a white cube building set against stark geometric cuts and folds in a carefully domed lawn that rolls against a bucolic landscape, is no more 'artificial' than a garden with a central sculpture. Yet Nature and industry were increasingly conceived as being compatible and even interchangeable, such as in Paolo Soleri's architectural ecologies (arcology) where cities were formally entwined with their landscape (Newitz, 2013a). Using this approach, more ecological outcomes could be achieved by producing more ordered forms of Nature and could be equally applied to the design and manufacture of objects and processes. For example, Robert Frosch and Nicholas Gallopoulos developed the idea of closed-loop exchanges within urban environments, where the waste processes of one system became the raw material for the next (Frosch and Gallopoulos, 1989). Janine Benyus further explored 
the idea of natural efficiency by promoting the practice of biomimicry (Beynus, 1997), which looks to Nature as a template for problem solving. Biomimicry typically observes original natural structures performing ingenious tasks, such as plant burrs attaching to sheep wool using tiny hooks, and translates these into design solutions like Velcro. It typically adopts a rather one-sided Romanticized view of Nature, which is regarded as providing us with sublime, pre-packaged solutions to help us achieve our collective ecological quest, while generally glossing over or ignoring its counterpart grotesquery. While biomimicry proposes to learn from Mother Nature (Beynus, 1997) by copying the shapes and functions of biological processes, the practice is mostly concerned with observing abstractions of the end products of hugely sophisticated material systems that are not static, but in continual flux. 'Mimicking' biological outputs ignores the sophisticated chemical hardware and software of natural systems, which are deeply entangled through the dynamic exchanges of metabolism, whose effects are spatialized by the environment. Biomimicry also concentrates on an incredibly small solution set, which is the outcome of many previous 'failures' and pays very selective attention to making its preferences in transforming identified 'solutions' into industrial materials such as plastics, metals and glass, which may then be incorporated into buildings. Biomimicry, therefore, is effectively an aesthetic practice, or a design version of the Just So Stories (Moran, 2008) and does not represent a systematic search of a solution space, which Kauffman calls the 'adjacent possible' (Kauffman, 2008, p.64). Rather, it is an ad hoc set of aesthetic or functional preferences made from an incompletely observed and biased set of possible choices. Yet, while biomimicry may inspire more attractive, mechanically efficient buildings, their relationship with the environment exists within the same paradigm as industrial buildings. Indeed, although McDonough and Braungart recommend keeping biological and technical metabolisms separate (McDonough and Braungart, 2002), Rachel Carson's chilling Silent Spring had already highlighted the inevitable leakage of invisible pollutants from industrial plants into natural systems to produce insidious effects that were 'not quite fatal' (Carson, 1962, p.29).

While irreconcilable differences between the technosphere and biosphere were sanctioned by the Club of Rome (Meadows et al, 1972), a third way existed which used the new science of complexity as an approach for understanding the extensive, multiscalar connections between even potentially unlike systems such as industry and the environment. Ecologist Arthur Tansley, who coined the term 'ecosystem' in 1935 (Willis, 1997; Odum, 1971), set out a new paradigm for thinking about material relationships through the existence of functioning wholes, comprised of highly integrated parts that could not merely be disentangled and dissected into dichotomous, deterministic states. While cities have historically been likened to 'organisms' since Aristotle's time, over the course of the late 20th century, cities have been increasingly viewed as complex structures, and the term 'ecosystem' has been used to indicate the multiple urban relationships that form our metropolitan environments and give rise to architectural events. Yet, the appreciation of the systemic nature of cities has done little to dispel 
the fundamental dichotomy between human development and Nature. Rem Koolhaas notes that not only has 'the sum total of current architectural knowledge [not] grown beyond this opposition' (Koolhaas, 1995) ${ }^{19}$ but also observes the downside of excessive formal solutions within social spaces, where glamorous forms alienate their populations by eroding cultural and historical values. ${ }^{20}$ Stewart Brand, in particular, identified a new emerging order of technology in modern computing which was compatible with ecological systems that could potentially evolve alongside each other. The mutually overlapping frameworks of cities, ecosystems and the fluid medium of 'cyberspace' shared the same complex, fundamental organizing principles. Digital computing rapidly became the platform for cybernetic, 'whole-systems' technologies, which could potentially align the goals of technology and the natural world (Brand, 2009). Cyberspace enabled the complexity of our reality not only to be conceived but also visualized according to the principles of complex systems, by revealing the relationships between otherwise intangible elements, such as the map of the Internet. Indeed, envisioning digital technologies as being compatible with complex processes such as natural systems through the field of cybernetics was one of the most important ways in which the Whole Earth discourse helped prepare the way for the digital revolution of the 1980s. However, the language of cybernetics is based on the metaphor of machines, which, coupled with the notion of Spaceship Earth, could begin to describe the Earth's systems in mechanical and geometric terms (Latour, 2013). The notion of a complex, terrestrial Nature-machine was enabled in cyberspace, whose visual software is informed by Euclidian geometry. Indeed, the digital domain enabled a new Cambrian explosion of morphological species whose possibilities were explored in the work of architects such as John Frazer (1995), Marcos Novak (1992), Neil Spiller (Pearce and Spiller, 1995), Greg Lynn (Lynn, 2000) and Lars Spuybroek (Spuybroek, 2011). This new language of possibility and interconnectivity enabled designers to imagine relationships between environments, objects and processes that were previously unrealizable, and has underpinned the practice of parametrics (Schumacher, 2009). The fluidity of cyberspace has also enabled academics such as Bruno Latour and David Harvey to describe the host of technological and natural elements that make up our urban environments as being the outcome of complex multi-scalar relationships (Latour, 1993; Harvey, 1996). Visualization of these concepts has informed the way that cities are (re)imagined through process-led relationships in which urban 'ecological' systems may be formed by the spatial configurations of all kinds (Hillier and Hanson, 1984), that are realized through horizontal couplings between agents through exchanges of culture, nature, power and capital. While

19 Koolhaas is referring to the cultural opposition of artifice and Nature.

20 Koolhaas notes that Singapore has kept up with its rapidly expanding populations by applying a tabula rasa developmental logic, which has subtracted any perceivable contextual background, adding only glamorous foreground. 
Philippe Rahm's 'Hormonorium' establishes ‘continuity between the living and the non-living' in the production of social spaces through new material relationships that operate through 'assemblage[s] of physiological devices acting on the endocrine and neurovegetative systems', its construction remains within the hierarchical traditions of architect as sole designer of systems (Philippe Rahm Architects, 2002). The new, systems-based ordering paradigm not only challenges the status of objects and geometries as the primary ordering units of architecture, but also invites agentized materials to inhabit non-classical methods of architectural production, as exemplified by Alison and Peter Smithson's 'new Brutalism' (Gissen, 2011) and post-structuralist architects like Bernard Tschumi (Tschumi, 2012), Gordon Pask (Pask, 1995), Cedric Price (Jacobs, 2011) and Lebbeus Woods (2012b). Further decentralization in the production of architecture is exemplified in naïve building projects such as postman Ferdinand Cheval's Palais Idéal (Dannies, not dated:a) and the steel Watts towers of Sam Rodia (Watts Towers, 2006-2013); on a smaller scale, caddis-fly larvae have been used by artist Hubert Duprat to produce ornate jewellery (Open Culture, 2013). More recently, growing artisan maker movements are further enabling distributed forms of architectural production (Morin, 2013) as well as artistic projects such as Roger Hiorn's 'Seizure' installation, a violet-blue crystal-coated building interior, grown in situ from solution (Searle, 2008). Furthermore, deanthropocentrized methods of architectural production, as proposed by Friedensreich Hundertwasser's manifestos (Hundertwasser, not dated; Hundertwasser, 1976), ${ }^{21}$ are increasing creativity at all levels of material organization, which are not the exclusive domain of architectural designers but may be engaged by many actants as a fundamental quality of the material realm. Indeed, Hundertwasser proposed that a 'decomposing solution should be poured over ... glass walls and smooth concrete surfaces, so the moulding process can set in' (Hundertwasser, 1976). By subverting the expectations of architecture, new materials, processes and forms of social organization may be free to produce new methods of architectural production. These are essential for the development of truly subversive forms of material creativity that open up a convergent space for the entanglement of artificial and natural processes. These alternative modes of architectural production erode the classical dichotomy between architecture and landscape and transform urban landscapes into post-natural fabrics, which are new forms of ecology in which technology is seamlessly and coherently entwined with natural systems (see Fig. 3.4).

Indeed, post-natural architects are not master planners, but expert facilitators and collaborators. They work with the innate creativity of many heterogeneous actants to midwife spatial programs into material expressions that reinvent conditions for living. To be fully realized, such possibilities require an alternative technological platform that is not constrained by the aestheticisms of Nature, or the geometry of machines.

21 Read by Hundertwasser at Seckau Abbey, Styria, 4 July 1958. 


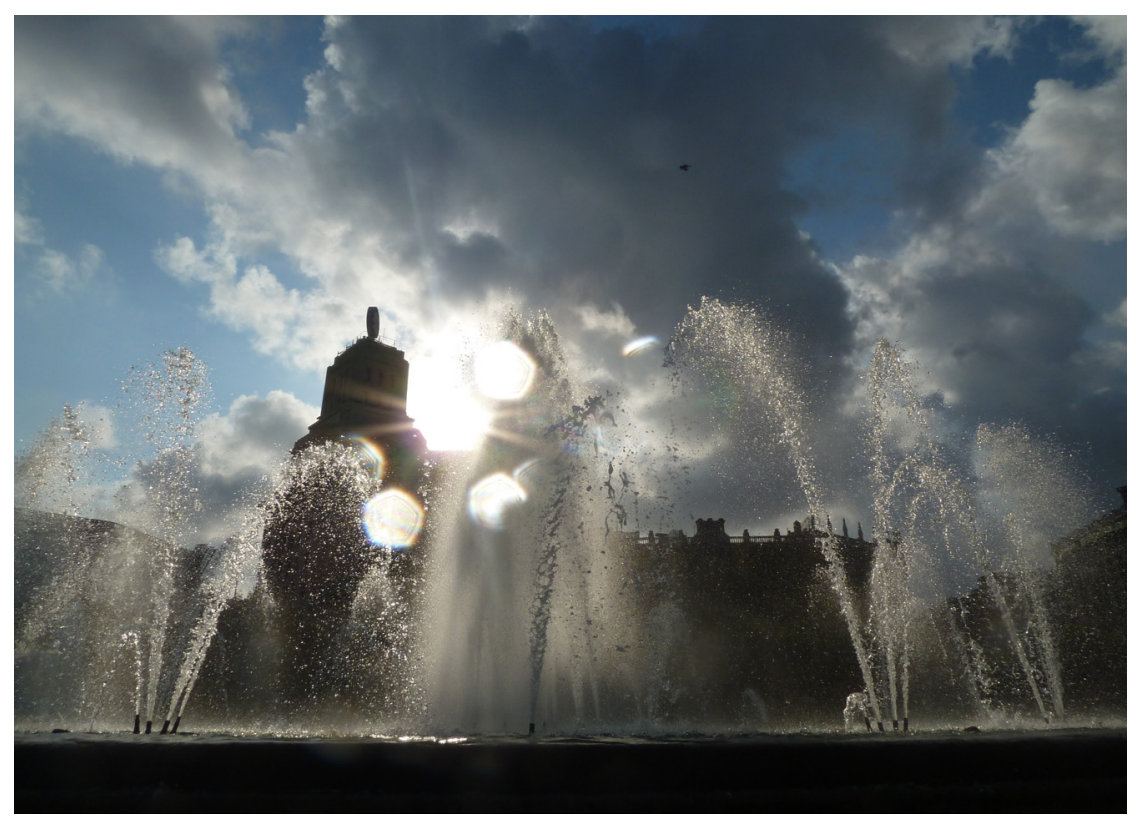

Figure 3.4: This fountain in Plaça de Catalunya, Barcelona suggest provokes the idea of postnatural landscapes actively evolving within urban communities. Photographs and collage, Rachel Armstrong, November 2011.

David Gissen proposes that such a fabric is 'sub-natural', being deeper, messier and more primordial than our cultural expectations of Nature. He suggests that such subversive materiality may constitute the 'architectural reconstruction of nature' where 'we can be surrounded by things that are absolutely alive without transforming them into simplistic expressions of life' (Gissen, 2011). Yet, form-finding alone in the reconstruction of material paradigms is not sufficient to build mutually reinforcing relationships between actants. Indeed, Christian Groothuizen proposes that: 'Artificial ecologies must be able to sense and respond to a variety of natural and artificial stimuli at a multitude of scales, and provide a platform for real ecologies to re-establish' (Pohl, 2011). In appreciating that the difference between natural and technological landscapes is underpinned by cultural aesthetic preferences (Morton, 2007), the coupling of systems and the kinds of social organizations produced by these entanglements become more important in bringing changes in the production of architecture than any specific contributions by the participating technologies. For example, Liam Young proposes that near-future landscapes will be entanglements of robotics, biotechnology and ubiquitous computing, which will give rise to new specimens of biotech creatures (Young, 2011). This forward-looking, propositional view of 'architecture of the future' is also shared by R\&Sie(n), who anticipate 'unimaginable post-human landscapes and "things" that are hybrid mixtures of 
organic and inorganic material' (Frichot, 2011). Such multitudinous, heterogeneous couplings between actants and assemblages do not coexist without difficulties or conflicts, but through managing the different relationships between the many scales of existence, in which architectural design has the potential to play an increasing role. Latour notes that such groupings deal with 'life' and occupy space in unique ways that define their specific territories. The borders of these terrains are not destined to be harmonious and infinite but are locally defined and may indeed provoke conflict between neighbouring systems. Latour proposes that our 21st century challenges relate to limiting the prospective wars of our world over the ordering of space through the actions and needs of different territories and different bodies (Latour, 2013).

To establish what kinds of materials, infrastructures and technologies may literally, rather than propositionally, give rise to post-natural fabrics, I directed my reading towards investigating practices that were working with lifelike materials. I was particularly looking for agents that spoke to the idea of 'sub-natural' materials (Gissen, 2011) and could propose how such raw forms of matter could be applied technologically within an architectural design context.

\subsubsection{Bio Design}

... the romantic tradition ... depicts nature in terms of a sublime pantheism ... the scientific tradition ... depicts nature in terms of a mundane positivism. (Bok, 2001, p.93)

Nature may be regarded as a Romantic technology (Bowie, 1995) that has experienced a very slow evolution owing to conservative views that characterize our cultural expectations of Nature (Morton, 2007). Yet, recent developments in the field of biotechnology have changed the practice of biology and the possibilities of working with natural systems from being a backward-looking, descriptive practice - one that simply describes the way that things are - into a forward-looking approach that imagines what they could be, with the goal of engineering living systems to produce modified biological or lifelike systems. The rise of modern biotechnology began in 1985 with the invention of the polymerase chain reaction (PCR) technique by Kary B. Mullis (Smithsonian Institution Archives, 2004), which became the catalytic technology needed to fuel the rapidly developing insights into genetics. PCR allowed scientists to make millions of copies of even the tiniest samples of DNA and greatly accelerated the rate at which previously painstaking genetic experiments could take place. This enabled the entire genome of a simple organism, Caenorhabditis elegans, to be sequenced (Hodgkin et al, 2011). As more organisms joined the ranks of genetically decoded creatures, it was evident that the sequencing of the three billion base pairs of human genetic code was within sight, and international research groups collectively worked towards decoding the entire human genome. This monumental venture was called the Human Genome Project, and generated intense competition 
between research groups to find more efficient ways of reaching their goal. New biotechnologies seemed to be invented almost daily, and it was already apparent in the early 1990s that the full DNA sequence of the human genome would soon be known (Jablonka and Lamb, 2006, p.1).

The formal sequencing of the human genome in 2003, and recent biotechnological engineering feat by J. Craig Venter's team who produced the world's first organism with a synthetic genome (Gibson et al, 2010), dubbed 'Synthia' by the popular press, have heralded the current age of synthetic biology, which represents a new manufacturing process that does not rely on petroleum as a substrate but directly harnesses natural processes by commanding their cellular machinery (Venter, 2007). Although the advent of molecular biology and the discovery of DNA (Watson and Crick, 1953) provided techniques that enabled access to the microscale, designers have not historically had access to this space owing to institutional, conceptual and technological challenges and therefore these tools and approaches have not been central to the organicist debates.

Yet, recent changes in policy with the advent of Artscience projects championed by organizations such as the Wellcome Foundation (Wellcome Trust, not dated) and Harvard University (The Laboratory at Harvard, 2013), coupled with a high-profile campaign for public engagement in science (Guardian, 2012), have provided a new generation of designers with access to tools, materials and associated methods that are expanding designers' reach (Armstrong, 2008a; Armstrong, 2008b; Armstrong, 2010d). Biotechnology enables designers to work directly with the natural world, and frees them from the obligation to mimic its forms and processes (see Fig. 3.5).

Bio Design (Myers and Antonelli, 2013) is an emergent, experimental design space that incorporates ideas implicit in modern biotechnology and views biological systems as the subject, canvas and medium for design across a range of contexts (Gambino, 2013). This movement proffers an ecological agenda that seeks alternatives to industrial methods of production, with beneficial environment impacts. Yet, this design platform is still emerging and the specific technologies and methods that characterize the practice are not formalized. Consequently, Bio Design projects are often not fully realized and invoke possible as well as actual designs. This presents a research opportunity in evaluating the current approaches and techniques to identify technological and methodological gaps in the field.

Bio Design operates across a very broad spectrum of practices that includes the direct manipulation of native biology, such as 'Cattedrale Vegetale' by Giuliano Mauri, which fashions firs, hazel and chestnuts into an avenue of arches (Myers and Antonelli, 2013, pp.32-35). Greg Bosquet's 'Harmonia 57' incorporates plants directly into more traditional architectural materials such as porous concrete (Myers and Antonelli, 2013, pp.22-25), and Henk Jonkers ‘Bioconcrete’ seeds natural extremophile bacteria, which can tolerate extreme alkalinity, within traditional concrete mixes to bestow 


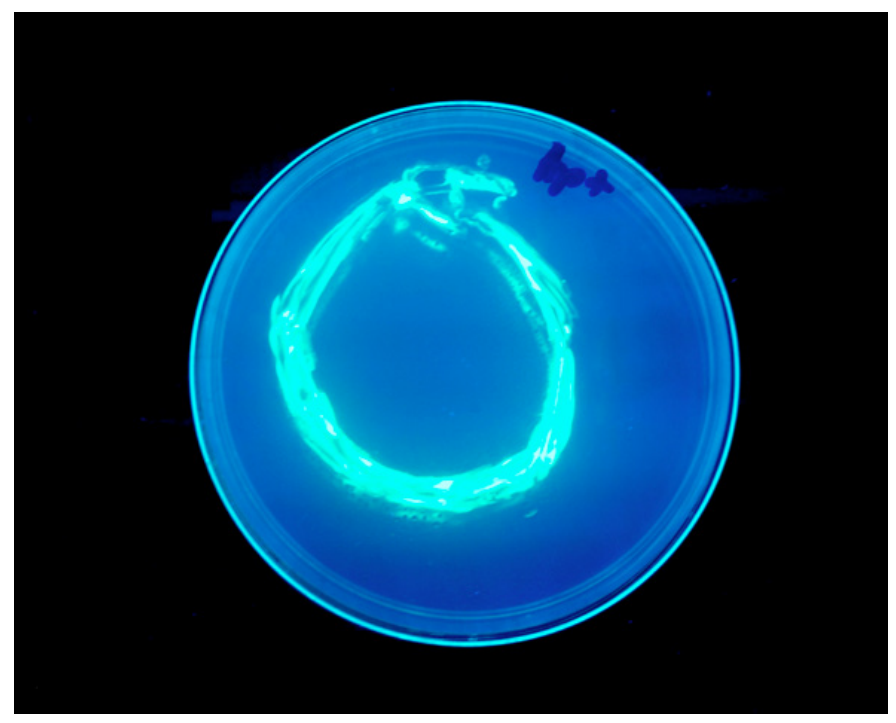

Figure 3.5: This drawing of an ouroboros was made using a sterile loop to apply a genetically modified strain of $E$. coli to a nutrient medium. The bacteria had been transformed by inserting a gene that expressed a green fluorescent protein, which produces bioluminescence under dark light. The experiment was carried out at the Cantacuzino National Institute for Research and Development in Microbiology and Immunology (NIRDMI), Bucharest, Romania, with senior research scientist Alexandru Vladimirescu, supported by a Darwin Now Award from the British Council. Photograph of bacterial drawing, Rachel Armstrong, July 2009.

them with self-healing properties. ${ }^{22}$ The hardy organisms mixed into the cement are activated when tiny cracks in the concrete let in water and produce a calcified sealant that prevents further progression of the micro-fractures (Mandel, 2013; Myers and Antonelli, 2013, pp.80-81). In fact, bacterial metabolisms are frequently used in Bio Design as 'workhorse' alternatives to industrial processes, which would usually require large amounts of heat to perform tasks such as brick manufacturing. Ginger Krieg Dosier's 'Bio Bricks', however, uses no heat and encourages bacteria to transform sand grains into sandstone (Myers and Antonelli, 2013, pp.78-79). Other microorganisms, such as mycelia, ${ }^{23}$ are used for making biological building materials like Eben Bayer's 'Ecocradle' product packaging (Myers and Antonelli, 2013, pp.106107) and Suzanne Lee's microbial cellulose cloth, which is produced by a blend of yeast, green tea and sugar (Myers and Antonelli, 2013, pp.108-111). Bio Design also incorporates more speculative work such as 'Meat House' by Terreform ONE that

22 Concrete is an extremely alkaline material; however, Jonkers' extremophiles can endure these conditions despite this noxious environment that is lethal to most other life forms.

23 Mycelium is the term used to describe the branching networks of fungi. 
envisages growing leathery skins around buildings using tissue culture and largescale three-dimensional printing techniques. In practice, however, tissue culture is prohibitively expensive for architectural projects, costing around $\$ 1,000$ for three square centimetres of skin (Armstrong and Spiller, 2011). Moreover, cultured tissues are not yet scalable, since traditional buildings do not possess suitable infrastructures to support and nurture living tissues and need to be kept in a sterile environment to protect it from bacterial infection, which is impractical. Indeed, Bio Design considers a range of uses for genetic manipulation, such as Alberto T. Estevez's 'Genetic Barcelona', where cities are imagined to be lit by genetically modified trees that glow with green fluorescent protein (GFP) (Myers and Antonelli, 2013, pp.68-69).

Such propositions of incorporating synthetic organisms into social spaces raise important questions about public health and safety, as well as starting important cultural conversations about how living spaces with 'transformed' genetic materials may be inhabited. Other architectural projects speculate even further into the future, such as Conny Freyer and Sebastian Noel's project that proposes strange, transformed plants, which are reminiscent of an applied 'Parallel Botany' (Lionni, 1977), will manage the health of urban environments (Myers and Antonelli, 2013, p.178-181). Indeed, Bio Design actively engages with the technological and cultural challenges implicit in the advent of modern biotechnology, where lively materials may not only impact on our lives through the kinds of substances they produce, but may also become entangled with our cultural, moral and ethical systems. For example, SymbioticA's 'Victimless Leather' (Schwartz, 2008) offers another way of producing meat than by slaughtering animals and raises questions about how meat-yielding tissue cultures should be raised (Armstrong, 2012a). Although Bio Design agitates for a new paradigm of practice, there is a significant risk that it will fail to do so. This is partly due to the immaturity and expense of biotechnologies outside of a medical or industrial setting, but also because of the difficulty in reaching a critical escape velocity by distinguishing itself from a dominant machine-led culture, which may simply assimilate Bio Design into its system as 'little soft machinery'. ${ }^{24}$

This particular literature survey identified that, within the field of Bio Design, there are opportunities to establish new ways of working with lifelike materials in both real and speculative ways. Yet, I wanted to differentiate these approaches from neo-environmental, industrial systems that regard Nature as a robust consumable. So, I directed my reading towards identifying a discrete set of materials and approaches that encapsulated the principles of vibrant matter (Bennett, 2011).

24 The term 'little soft machinery' was architecturally coined by Neil Spiller (2007, pp.202-224) to refer to William Burrough's novel about how control mechanisms invade the human body (Burroughs, 1961). 


\subsubsection{Vibrant Matter}

Bennett's theory of vibrant matter establishes a philosophical and cultural context that proposes that we might achieve more ecological outcomes if we observe how events may change if we give the force of 'things' more due (Bennett, 2010, p.viii). While Bennett draws on the vitalist tradition to attribute power to the material world (Bennett, 2010, pp.83-84), my research asserts the capacity for matter to act firmly within the material realm as an expression of the paradoxical laws of quantum physics. These powers may be viewed as 'sub-natural' forces (Gissen, 2011), which are encapsulated in the origins of life sciences that are concerned with the twilight zone between animate and inanimate systems (Luisi, 2010). The innate forces of vibrant matter may be further explored through associated technological research platforms in scientific fields such as combinatorial chemistry (Kauffman, 2011) and synthetic biology. I sought to identify a suitable system that could embody the cultural agendas implicit in vibrant matter that exhibited spontaneously lively behaviour which could be observed at the human scale. My aim was to establish an experimental platform which could be safely and ethically studied in the laboratory as a way of investigating the principles of vibrant matter as a material substrate for architectural design.

I began my search for these materials in the origins of life sciences, where Fredrich Wöhler first demonstrated the continuity between living and non-living systems by synthesizing biological molecules from non-biological ones (Wöhler, 1828). This set the scene for a revolution in chemistry, namely the quest to build living systems from non-living ingredients. This went in opposition to the work of the alchemists, who sought simplification through the distillation of essences that made up the world; for example, aqua vitae - the essence of life. Since the Enlightenment, chemists and gentleman scientists such as Johann Rudolf Glauber (Glauber, 1651), Frederic Ferdinand Runge (Runge, 1850), Moritz Traube (Traube, 1867), Raphael E. Liesegang (Liesegang, 1869), Otto Bütschli (Bütschli, 1892), Boris Pavlovich Belousov (Belousov, 1959) and Vladimir Yevgenyevich Zhabotinsky (Zhabotinsky, 1964) began investigating the complex material processes that underpinned the transition from non-living to living matter and challenged vitalistic perspectives ${ }^{25}$ by establishing that chemical systems possessed biotic qualities (see Fig. 3.6).

I first encountered the most striking and experimentally appropriate system of chemical self-assembly during the Artificial Life XI conference in 2008 (Artificial Life XI, 2008). Takashi Ikegami's keynote talk outlined how self-assembling droplets could be produced by a carrier oil system with a metabolism (Hanczyc et al, 2007) (see Fig. 3.7). Although these droplets were not technically alive, they exhibited a range of behaviours such as movement, sensitivity and the production of microstructures.

25 Vitalism proposed that living things are fundamentally different to non-living ones because they possess an intangible essence such as soul or consciousness. 


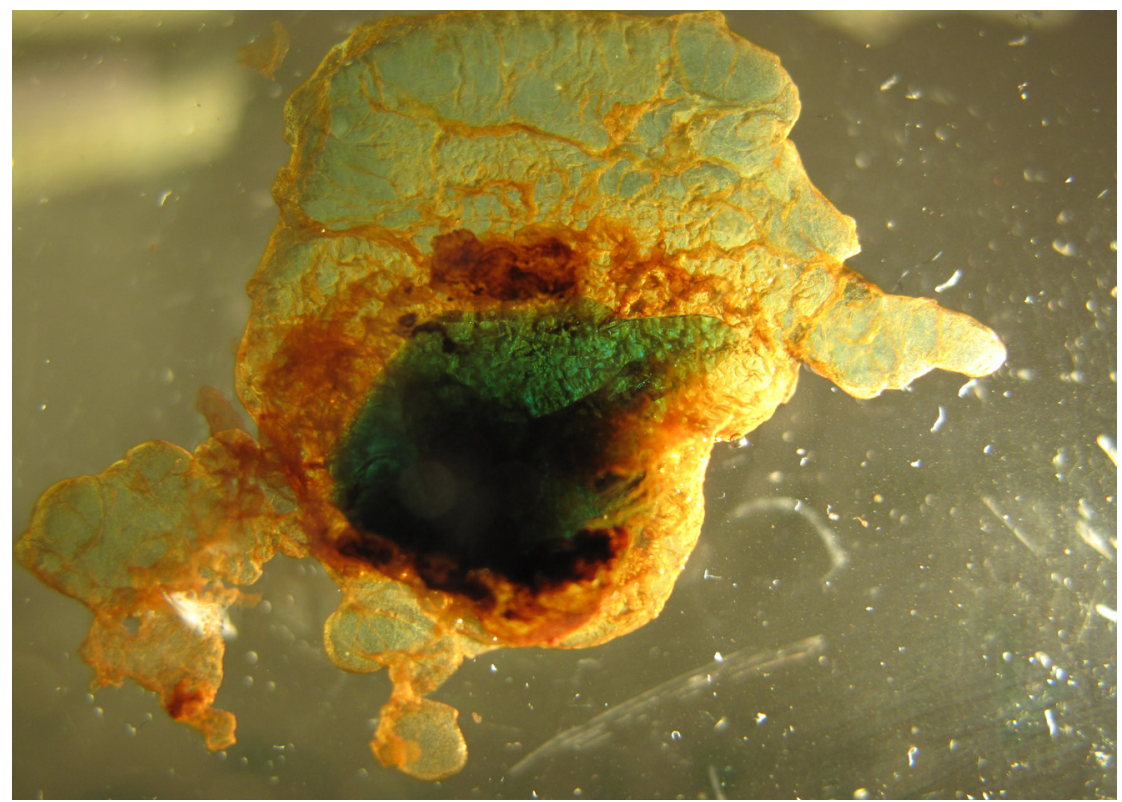

Figure 3.6: This 'artificial plant-like' Traube cell was grown by adding a crystal of copper II sulphate to a weak $0.1 \mathrm{M}$ solution of potassium hexacyanoferrate. Photograph, courtesy Philip Beesley Architect, July 2009.
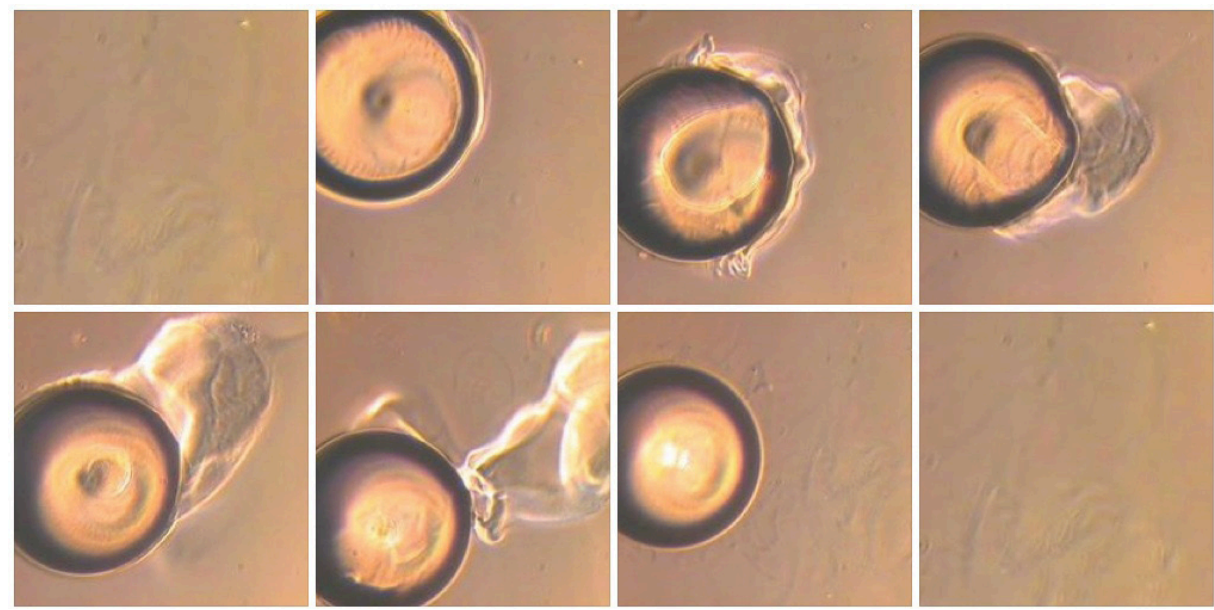

Figure 3.7: This series of images of a benzene droplet with a simple anhydride metabolism is exhibiting complex lifelike behaviour including movement and the shedding of a chemical 'skin'. Movie stills taken at intervals of $30 \mathrm{~s}$, following the addition of an oil droplet to an aqueous solution, courtesy Martin Hanczyc, August 2007. 
Yet, dynamic droplets had no formal applications other than being considered as a possible platform for 'soft robots'. ${ }^{26}$ This suggested dynamic droplets possessed technological potential and could conceivably work in a qualitatively different way to machines. Indeed, a focused literature survey revealed that these dynamic droplets (Hanczyc et al, 2007; Toyota et al, 2009) could spatially distribute matter, respond to changes in their environment and produce a chemical skin that was vigorously shed like a synthetic amniotic sac and, therefore, may be of architectural relevance. Martin Hanczyc outlined the scientific history of the droplets that had been developed as research tools in the origins of life sciences (Hanczyc, 2008). Other research groups were also investigating dynamic chemical systems using amphiphiles (oils with detergent-like qualities) such as reverse micelles (water in oil droplets stabilized by a surfactant) (Pileni, 2006) and oil droplets in aqueous media (Hanczyc et al, 2007; Toyota et al, 2009); but, although these dynamic chemical systems produced lifelike effects, they had not been used as a technological platform. I therefore sought to establish a variety of practical approaches for working with dynamic, lifelike chemical systems as a possible form of technology and model systems for demonstrating the principles and potential practice of using vibrant matter in architectural design.

\subsubsection{Morphological Computing}

Since dynamic droplets had not been architecturally examined, a literature survey identified ways of working with these agents in a technological capacity so they could be incorporated into a portfolio of design tactics that could execute spatial programs. Of particular interest were a range of alternative forms of computing that used complex, chemical systems as the programming language and hardware called 'natural computing', following Alan Turing's interest in the computational power of Nature (Turing, 1936). 'Natural' computers have been made using DNA, light, modular bricks and paper, and therefore provided an appropriate context for exploring how non-mechanical, physical systems might operate as technological platforms (Denning, 2007; Zyga, 2013). Currently the field includes a broad range of mutually supportive, overlapping practices which include approaches such as digital modelling of biological systems (Paun, 2005) and the manipulation of chemical patterning systems (Aron, 2011). Within the field of natural computing, 'morphological computing' (Pfeifer and Iida, 2005) was identified as a suitable platform to deal with the computational powers of material processes and could potentially respond to spatial programs to achieve directed effects. Owing to the early stages of development

26 Soft robotics is being a material movement within robotics that does not use 'hard' bodies that are composed of metallic structures on 'conventional bearings' that do not exist in Nature but a portfolio of softer, more flexible materials (Whitesides Research Group, 2011). 
of this research field, the design and engineering tactics of morphological computing are diverse and have not been formalized into a particular rule set. The knowledge gap identified was, therefore, how dynamic droplets could be used as a material, and infrastructure and technology that could function as an alternative production platform to machines.

\subsection{Summary}

My literature survey draws from overlapping, multidisciplinary research fields and practices. It suggests that by using dynamic chemistries at far from equilibrium states potential applications of lively materials for architectural design may be systematically interrogated. Dynamic droplets appear to provide a viable model system for establishing the possibility of a practice that incorporates the principles of vibrant matter with precedents within organicism and Bio Design. These may be meaningfully applied in an architectural design context and manipulated using morphological computing techniques. The following chapters explore the research opportunities identified in my literature survey and develop them towards testable design propositions. 